\title{
The Process of Weaning from Mechanical Ventilation
}

Hernán Aguirre-Bermeo, MD and Jordi Mancebo, MD, PhD

Intensive Care Unit, Hospital de la Santa Creu $i$ Sant Pau, Barcelona, Spain

\section{ABSTRACT}

Mechanical ventilation is a common process in intensive care units. The weaning period has to be initiated as soon as possible because a delay in recognition that weaning can begin may prolong the duration of mechanical ventilation unnecessarily. The inappropriate management of weaning could influence outcomes; therefore, patients on weaning require continuous attention and intervention. The main objective of this review is to provide a description of the entire scenario and update on outcomes and common recommendations for the correct management of this complex process. The role of modern ventilator modes and non-invasive mechanical ventilation are discussed. Finally, the description and outcomes of a group of patients who have poor outcomes (prolonged weaning group), the importance of their identification, and suggestions for their general management are also presented. (BRN Rev. 2016;2:185-97)

Corresponding author: Jordi Mancebo, jmancebo@santpau.cat

Key words: Mechanical ventilation. Prolonged mechanical ventilation. Weaning. Weaning groups. 


\section{INTRODUCTION}

Mechanical ventilation (MV) is one of the most common procedures in the intensive care unit (ICU) ${ }^{1}$. The main goal of $\mathrm{MV}$ is to help restore gas exchange and reduce the work of breathing by assisting respiratory muscle activity ${ }^{2}$. Weaning is conducted differently around the world and several modalities are used during weaning ${ }^{3-5}$.

Weaning is the process of withdrawal of MV. Weaning starts when the patient improves the underlying disease and the responsible physician suspects that he/she can breathe without ventilator assistance. This process has a variable duration and it typically starts by performing a spontaneous breathing trial (SBT). In the majority of patients, the first SBT is followed by an extubation of the trachea. Other patients, however, do not pass the first attempt to wean and will thus require a progressive withdrawal of ventilator assistance. The ability of physicians to predict whether patients can maintain spontaneous breathing after MV has been extensively studied $^{6,7}$. Therefore, in order to improve the outcomes, the patients that can breathe without ventilator assistance have to be identified early so that the weaning period is kept as short as possible.

\section{WEANING PROCESS}

Tobin and Jubran ${ }^{8}$ divide the weaning period in seven stages as follows (Fig. 1):

The first stage (pre-weaning) is a period when the patient's clinical condition and gas exchange does not permit to start weaning (i.e. patient with multiorgan dysfunction syndrome and/or high positive end-expiratory pressure and fraction of inspired oxygen $\left[\mathrm{FIO}_{2}\right]$ levels). Actually, some patients never get beyond this stage.

The second stage starts with the physician's suspicion that the patient can begin the weaning process. Weaning can be initiated if some conditions are reached. These conditions are: (i) improvement of the underlying disease; (ii) an adequate gas exchange; (iii) stable hemodynamics; (iv) adequate performance of the respiratory muscles with correct management of respiratory secretions; and (v) no major metabolic and/or electrolytic disturbances ${ }^{9,10}$. The correct management of respiratory secretions has to be evaluated because the patients need to protect their airway and clear the secretions with an effective cough. The stimulation of cough reflex with a suction catheter and the amount of secretions have to be considered by the physician or nurse in charge. Pressure support ventilation (PSV) is the most often used assisted modality ${ }^{11}$ and synchronized intermittent mandatory ventilation has demonstrated to be the less efficacious modality ${ }^{9,12}$. Recently, closed-loop modalities have been used at this stage to gradually decrease ventilator assistance.

The third stage is the period for the assessment of readiness to wean through a correct interpretation of physiologic measurements. The rapid shallow breathing index is recommended at this stage ${ }^{13}$. This index is the ratio of breathing frequency over tidal volume $\left(\mathrm{f} / \mathrm{V}_{\mathrm{T}}\right)$. It appears to be the most useful method at bedside. If the value is $<105$ breath/ $\mathrm{min} / \mathrm{l}$, the process of weaning can continue. This index, however, has some false positive 


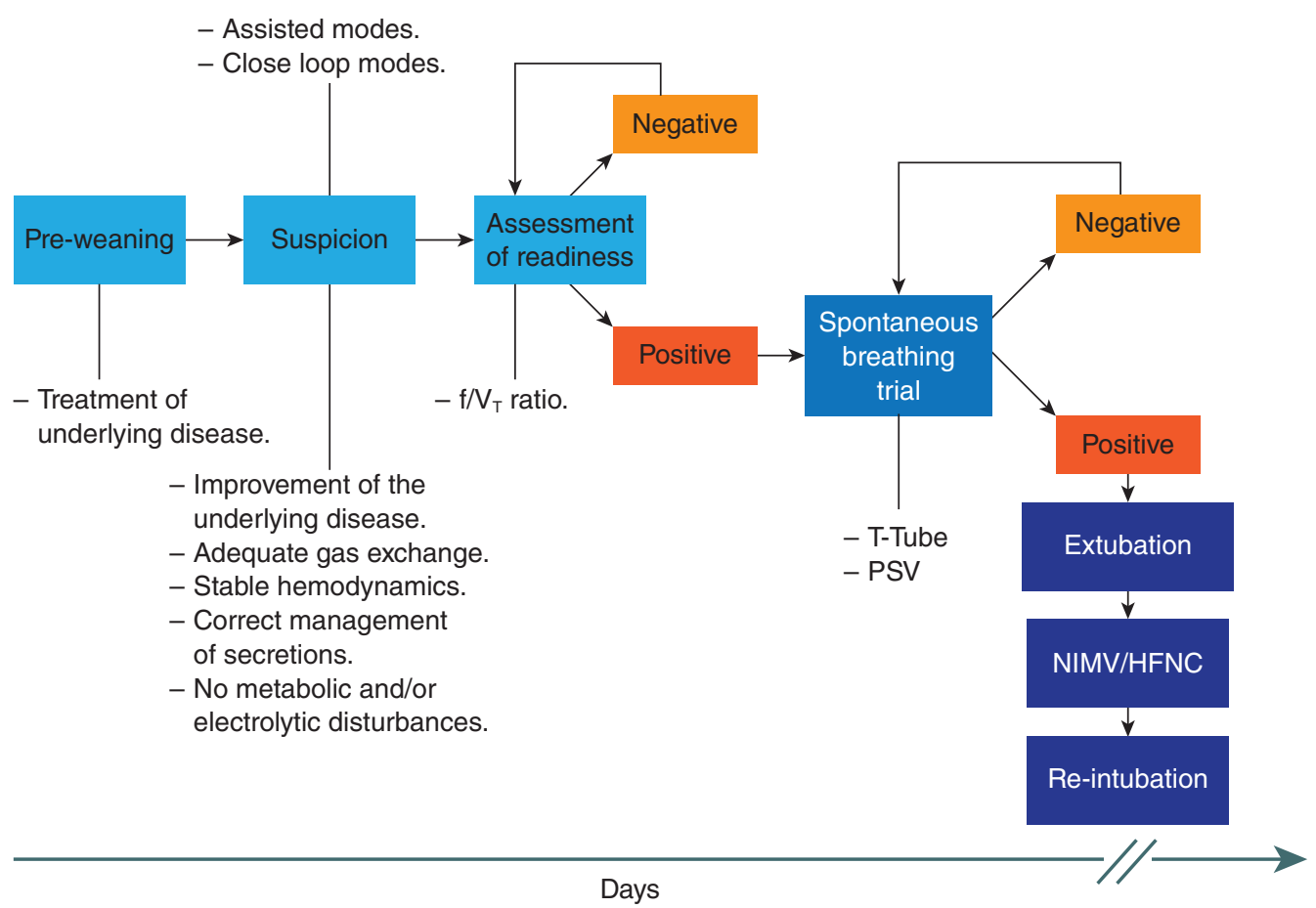

Figure 1. Weaning process.

$f / V_{T}$ ratio: ratio of breathing frequency over tidal volume; HFNC: high-flow nasal cannula; NIMV: Non-invasive mechanical ventilation; PSV: pressure support ventilation; SBT: spontaneous breathing trial.

and false negative results, depending on the patient's underlying condition ${ }^{7}$. At the bedside, if the result of the rapid shallow breathing index and the clinical judgment is favourable, the physician can continue with the next stage.

The fourth stage is to perform a SBT. This can be conducted without ventilator assistance (T-tube) or with low-pressure support level (7-8 $\mathrm{cm} \mathrm{H}_{2} \mathrm{O}$ ) at zero end-expiratory pressure. The disadvantage of the T-tube trial is related to the absence of a connection to a ventilator; therefore, the patients have to be closely supervised. The physician should remember that endotracheal tube narrowing is common during MV and increases with the duration of intubation ${ }^{14}$. The progressive reduction in internal diameter of the endotracheal tube (i.e. inspissated secretions, others) increases airflow resistance and thus the effort to breathe. Data indicate that the airflow resistance of endotracheal tubes at the time of extubation is much higher than at the time of intubation, thus increasing the respiratory muscle work ${ }^{15}$. The optimal duration of the SBT trial is at least 30 minutes and no more than 120 minutes. Spontaneous breathing trials with pressure support or T-tube appear to be suitable methods for evaluation the capacity of spontaneous breathing ${ }^{16}$. However, in difficult to wean patients, the best method to analyse the capacity for spontaneous breathing is T-tube because pressure support could modify the breathing pattern, inspiratory muscle effort, 
and cardiovascular response as compared to T-tube $^{17}$. During SBT, the physician has to take into account signs of increased patient effort (increase in the respiratory rate, the use of accessory muscles, diaphoresis), cardiovascular instability, and abnormal mental status (agitation and/or anxiety). The following signs and symptoms indicate an inability to tolerate SBT: (i) respiratory rate $>35$ per minute; (ii) systolic blood pressure $\geq 160 \mathrm{mmHg}$ or $\leq 90 \mathrm{mmHg}$, heart rate $\geq 140 \mathrm{bpm}$ or increased by $25 \%$ or more over baseline or new arrhythmia; (iii) worse level of consciousness, sweating, or agitation; (iv) hypoxemia $\left(\mathrm{PaO}_{2}\right.$ $<60 \mathrm{mmHg}$ with inspired fraction $\geq 0.5$ ); (v) respiratory acidosis $(\mathrm{pH} \leq 7.30)$.

Stage five refers to extubation if the SBT is well tolerated or the reinstitution of MV if the SBT failed. Daily SBT have to be performed in patients who are not weaned at this stage.

The sixth stage implies the use of non-invasive mechanical ventilation (NIMV) after extubation in specific groups of patients. Its indications are detailed below.

Finally, the seventh stage refers to re-intubation.

\section{PATHOPHYSIOLOGY \\ OF WEANING FAILURE}

\section{Respiratory Pump Failure}

When the patient's capability cannot balance the respiratory mechanical load, a respiratory pump failure may ensue. This is the most common cause for weaning failure ${ }^{18-21}$. The deterioration in respiratory system mechanics in patients who fail the weaning trial is characterized by an increase in intrinsic positive end-expiratory pressure (PEEP), and inspiratory resistance with a decrease in dynamic lung compliance ${ }^{22}$. Physicians must take into account that the components of the ventilator circuit, including endotracheal tubes (size, deposit of secretions, curvatures, humidifiers), can increase resistance to airflow and the resistive component of the work of breathing in patients breathing spontaneously ${ }^{15,23}$.

\section{Heart Failure}

Another important and preventable cause of weaning failure is heart failure. During SBT, an increase in blood pressure, heart rate, oesophageal pressure swings (indicating an increase in respiratory muscle effort), and the pulmonary capillary wedge pressure suggest the presence of heart failure ${ }^{24}$. In this scenario, an increased left ventricular preload and afterload occurs, accompanied by an increase in catecholamine levels that contribute to higher oxygen consumption with consequent heart failure and pulmonary oedema ${ }^{25,26}$, thus creating a vicious circle.

Nowadays, there are non-invasive tools to help physicians to make the diagnosis of cardiovascular dysfunction, such as echocardiography and measurement of plasma B-type natriuretic peptide (BNP). Mekontso-Dessap et al. ${ }^{27}$ suggested that a high BNP level before the SBT was an independent risk factor for weaning failure. In this study, the use of diuretic therapy increased the weaning success in patients in whom weaning failed with high BNP levels. Afterwards, the same authors performed a randomized, controlled, multicenter study in 304 patients. They compared 
a BNP-driven $(n=152)$ strategy with a usual care physician-driven $(n=152)$ strategy of fluid management during ventilator weaning ${ }^{28}$. The BNP-driven group had more negative fluid balance $(-2.3$ versus -0.21 ; $\mathrm{p}<0.001)$. Time to successful weaning including invasive and non-invasive ventilation was significantly shorter with the BNP-driven strategy as compared to usual care (49 versus 74 hours; $p=0.05)$. The authors found that the effect on weaning time was mainly driven by patients with left ventricular systolic dysfunction.

\section{Other Causes of Weaning Failure}

The weakness and muscle paresis acquired in the ICU is caused by different pathophysiological mechanisms ${ }^{29}$. Multiple organ system failure $^{30}$ with the use of neuromuscular blocking agents, associated or not with corticosteroids, may precipitate respiratory muscle weakness ${ }^{31,32}$. Malnutrition and immobilization also lead to muscle dysfunction and atrophy and can be another cause of weaning failure. The diaphragm seems more sensitive to disuse atrophy than other peripheral skeletal muscles ${ }^{33}$. Several previous studies ${ }^{33-36}$ have shown that critical illness and MV cause atrophy of human diaphragm myofibres. Finally, the abnormalities in muscle function are exacerbated by a decrease in oxygen supply to these muscles, metabolic acidosis, and by certain electrolytic and endocrinological disorders.

\section{CLOSED-LOOP MODALITIES AND WEANING}

Closed-loop modalities were developed to provide a continuous adaptation of ventilator assistance to patients' needs during 24 hours a day ${ }^{37}$ and to hasten the weaning from MV. The most commonly used closed-loop method is based on PSV (SmartCare ${ }^{\circledR} /$ PSV). This system continuously analyses the respiratory rate, tidal volume, and end-tidal carbon dioxide level, and adapts the level of pressure support in steps of 2-4 $\mathrm{cm} \mathrm{H}_{2} \mathrm{O}$ to keep the patient within a comfort zone. The system automatically tries to reduce the pressure level to a minimal value. At the time when the minimal low-pressure support is provided, a message on the screen recommends separation from the ventilator. Lellouche et al. ${ }^{38}$ found that the closed-loop modality decreased the duration of the weaning period compared to conventional PSV ( 3 versus 5 days; $\mathrm{p}=0.01$ ). The reduction in the weaning time was associated with a decrease in both the total duration of MV (7.5 versus 12.0 days; $\mathrm{p}=0.003$ ) and the ICU length of stay (12.0 versus 15.5 days; $\mathrm{p}=0.02$ ). In contrast to the positive findings of Lellouche and colleagues, Rose et al. ${ }^{39}$ reported that SmartCare ${ }^{\circledR} /$ PSV did not reduce weaning times. The differences on the results were due to the use of 1:1 patient-nurse ratio, the higher experience on weaning of the ICU staff, and the early exclusion of patients who tolerated PSV (within 24 hours). Schadler et al. ${ }^{40}$ found that this system decreased the duration of MV in a specific subgroup of patients (cardiac surgery). Finally, a study of Burns et al. ${ }^{41}$ compared SmartCare ${ }^{\circledR} /$ PSV versus a standardized weaning protocol and found that automated weaning patients had significantly shorter median times to first successful SBT ( 1 versus 4 days; $\mathrm{p}<0.001$ ) and to successful extubation ( 4 versus 5 days; $\mathrm{p}=0.01$ ).

Another closed-loop modality is adaptive support ventilation (ASV). In this modality, the 
physician has to set a maximum airway pressure and a percentage of minute ventilation (based on the ideal body weight) to be delivered to the patient. According to the pre-set user settings, and based in the Otis equation, ASV selects an optimal respiratory pattern in terms of respiratory rate, tidal volume, and inspiratory:expiratory ratio for mandatory breathing. Its main goal is to ensure an effective alveolar ventilation with a minimal work. Recently, a new modality based on ASV has been developed (IntelliVent-ASV ${ }^{\circledR}$ ). This mode adds a control of minute volume according to the end-tidal carbon dioxide monitoring and adjusts PEEP and $\mathrm{FiO}_{2}$ according to the peripheral oxygen saturation. Arnal et al. ${ }^{42}$ performed a short-term randomized study in 50 sedated patients and compared two hours of MV under conventional ASV modality versus two hours under IntelliVent-ASV ${ }^{\circledR}$ modality. They found that IntelliVent-ASV ${ }^{\circledR}$ as compared to ASV was safe and permitted to ventilate patients with less plateau pressure (24 versus $20 \mathrm{~cm} \mathrm{H} \mathrm{H}_{2} \mathrm{O} ; \mathrm{p}=0.005$ ) and less $\mathrm{F}_{\mathrm{i}} \mathrm{O}_{2}(40$ versus $30 \%$; $\mathrm{p}=0.001$ ), while maintaining similar oxygenation. Afterwards, Lellouche et al. ${ }^{43}$ compared IntelliVent-ASV ${ }^{\circledR}$ versus a local hospital protocol in 60 post-operative cardiac surgery patients. They confirmed that IntelliVent-ASV ${ }^{\circledR}$ was a safe modality and this mode required fewer interventions (148 interventions when applying the local hospital protocol versus five interventions when applying the IntelliVent-ASV ${ }^{\circledR}$ mode; $\mathrm{p}=0.001$ ).

Data obtained in selected populations indicate that closed-loop modalities perform at least as well as experienced medical staff to wean patients from $\mathrm{MV}$ and thus can be a useful addition to our armamentarium. These modalities, however, have not been designed to wean the most complex cases that can be encountered in the different clinical scenarios. Moreover, the use of these modalities is limited by the availability of the specific ventilator model and brand.

\section{NON-INVASIVE MECHANICAL VENTILATION}

There are clinical scenarios in which NIMV has an important role and its use may improve weaning outcomes.

\section{Non-Invasive Mechanical Ventilation in Difficult to Wean Patients With Chronic Obstructive Pulmonary Disease}

Selected patients with chronic obstructive pulmonary disease (COPD) who failed the first SBT (difficult to wean) may benefit from the immediate switch from invasive MV to NIMV after extubation ${ }^{44,45}$.

Nava et al. ${ }^{44}$ studied 50 COPD patients needing MV because of hypercapnic respiratory failure. Patients who failed the first SBT were randomized to receive invasive PSV or to be extubated and receive NIMV (delivered as pressure support ventilation) by facemask. The authors found a decrease in the duration of MV and in ICU length of stay in the NIMV group. Also, the survival rates at 60 days were $92 \%$ in the NIMV group versus $72 \%$ in the invasive ventilation group ( $p=0.009)$. Some years later, Girault et al. ${ }^{45}$ performed a study in similar patients. This study compared three strategies: NIMV immediately post-extubation, conventional invasive $\mathrm{MV}$, and extubation 
plus conventional oxygen therapy. They found that NIMV could improve the weaning results in COPD patients by shortening the intubation duration and reducing the risk of post-extubation acute respiratory failure, but no differences in mortality rates were confirmed.

\section{Non-Invasive Mechanical Ventilation in Patients at Risk of Developing Post-Extubation Respiratory Failure}

Patients with COPD and with chronic heart failure who tolerate the SBT but have high risk of developing post-extubation respiratory failure could benefit from NIMV after extubation. Using this approach, Nava et al. ${ }^{46}$ performed a trial in patients considered at risk of developing post-extubation respiratory failure (i.e. patients who had hypercapnia, congestive heart failure, more than one failure of a weaning trial, more than one comorbid condition, and so on). The patients were randomized to receive NIMV for $>8$ hours a day or standard medical therapy. They found a reduction of re-intubation rates in the NIMV group as compared to standard medical therapy ( 8 versus $24 \% ; p=0.03$ ) and in the risk of ICU mortality in the NIMV group $(-10 \%$; $p<0.01)$. Recently, Ferrer et al. ${ }^{47}$ performed a study in COPD patients who successfully passed a SBT and were extubated. The patients were randomized to NIMV or conventional therapy. They found both a reduction in respiratory failure after extubation ( 15 versus $48 \%$; $p<0.001)$ and mortality at 90 days (11 versus 31\%; $\mathrm{p}=0.02$ ) in the NIMV group as compared with conventional therapy.

\section{Non-Invasive Ventilation in Acute Respiratory Failure after Extubation}

The development of acute respiratory failure after extubation is a scenario where physicians may choose between re-intubating and resuming conventional $\mathrm{MV}$, or performing an NIMV trial. The less invasive condition for the patient could be the use of NIMV; however, the effectiveness of NIMV will depend on the underlying illness. Esteban et al. ${ }^{48}$ performed a multicenter, randomized trial to evaluate the effect of NIMV on mortality in postextubation respiratory failure. The patients were randomized to receive treatment with oxygen and usual care versus NIMV treatment and intubation if needed. The authors found that NIMV did not prevent the need for re-intubation or reduce mortality in unselected patients who had respiratory failure after extubation. The use of NIMV in acute respiratory failure after extubation is only recommended in specific populations, including those with chronic respiratory problems ${ }^{49}$ and selected postoperative patients ${ }^{50,51}$.

\section{THE ROLE OF HIGH-FLOW NASAL CANNULA}

Nowadays, the use of high-flow nasal cannula (HFNC) is increasing. The HFNC provides a high flow of heated and humidified oxygen administered via a nasal cannula and produces a low positive continuous airway pressure $\left(<4 \mathrm{~cm} \mathrm{H}_{2} \mathrm{O}\right)$, which is highly dependent on mouth-closing ${ }^{52}$. Maggiore et al. ${ }^{53}$ performed a study in MV patients who passed a SBT and had a $\mathrm{PaO}_{2} / \mathrm{F}_{\mathrm{I}} \mathrm{O}_{2}$ ratio $\leq 300 \mathrm{mmHg}$ at the end of the SBT. The patients were randomized to Venturi mask or HFNC during 
48 hours after extubation. The HFNC group had significantly better oxygenation $\left(\mathrm{PaO}_{2} /\right.$ $\mathrm{F}_{\mathrm{i}} \mathrm{O}_{2}$ ratio 287 versus $247 \mathrm{mmHg}$; $=0.03$ ) and significantly lower re-intubation rate (4 versus $21 \%$; $p=0.01$ ) as compared to the Venturi mask group. Stéphan et al. ${ }^{54}$ performed a study in 830 patients who had undergone cardiothoracic surgery. The patients were randomized to receive continuous HFNC or bilevel positive airway pressure (pressure support level of $8 \mathrm{~cm} \mathrm{H}_{2} \mathrm{O}$ and positive end-expiratory pressure of $4 \mathrm{~cm} \mathrm{H}_{2} \mathrm{O}$ ) for at least four hours per day. They did not find differences between the two groups in terms of treatment failure or ICU mortality. Recently, Hernández et al. ${ }^{55}$ studied patients at low risk for re-intubation. The patients were randomized to undergo either HFNC ( $n=264)$ or conventional oxygen therapy $(n=263)$ for 24 hours after extubation. They found that the use the use of HFNC compared with conventional oxygen therapy reduced the risk of re-intubation within 72 hours (4.9 versus $12.2 \%$; $\mathrm{p}=0.004)$.

\section{WEANING CLASSIFICATION}

An International Consensus Conference ${ }^{56}$ defined three groups of patients according to the weaning process, considering the duration of weaning and the number of SBT. In this consensus, weaning success was defined as extubation and absence of ventilatory support 48 hours following the extubation. If patients had a tracheostomy, weaning success was considered after 48 hours of absence of ventilatory support.

The patients were classified as follows (Table 1): (i) simple weaning, patients who proceed from
TABLE 1. Weaning groups according to the consensus conference classification ${ }^{56}$

\begin{tabular}{|l|l|}
\hline Group & Definition \\
\hline Simple & $\begin{array}{l}\text { Patients with successful weaning on the first SBT } \\
\text { attempt. }\end{array}$ \\
\hline Difficult & $\begin{array}{l}\text { Patients who fail initial SBT and require up to three } \\
\text { SBT or as long as } 7 \text { days of MV from the first SBT } \\
\text { to achieve successful weaning. }\end{array}$ \\
\hline Prolonged & $\begin{array}{l}\text { Patients who fail at least three SBT or require } \\
>7 \text { days of MV after the first SBT to achieve } \\
\text { successful weaning. }\end{array}$ \\
\hline
\end{tabular}

MV: mechanical ventilation; SBT: spontaneous breathing trial.

initiation of weaning to successful extubation on the first attempt; (ii) difficult weaning, patients who fail initial weaning and require up to three SBT or as long as seven days from the first SBT to achieve successful weaning; and (iii) prolonged weaning, patients who fail at least three weaning attempts or require $>7$ days of weaning after the first SBT.

A number of studies ${ }^{57-62}$ have evaluated this classification. In these studies, the incidence of the simple weaning group was $30-67 \%$ of all patients in whom an SBT was attempted (Fig. 2). The incidence of the difficult weaning group is reported to be around $20-40 \%$, and the incidence of the prolonged weaning group ranges from 6 to $30 \%$.

A summary of these studies ${ }^{57-62}$ indicates that simple and difficult weaning groups are similar in terms of mortality, re-intubation, tracheostomy, and ICU stay (Table 2). The prolonged weaning group, however, has been associated with worse outcomes and higher mortality (Table 2). Indeed, Peñuelas et al..$^{59}$ observed that a weaning duration longer than seven days identifies a subgroup of patients at increased risk of death. 


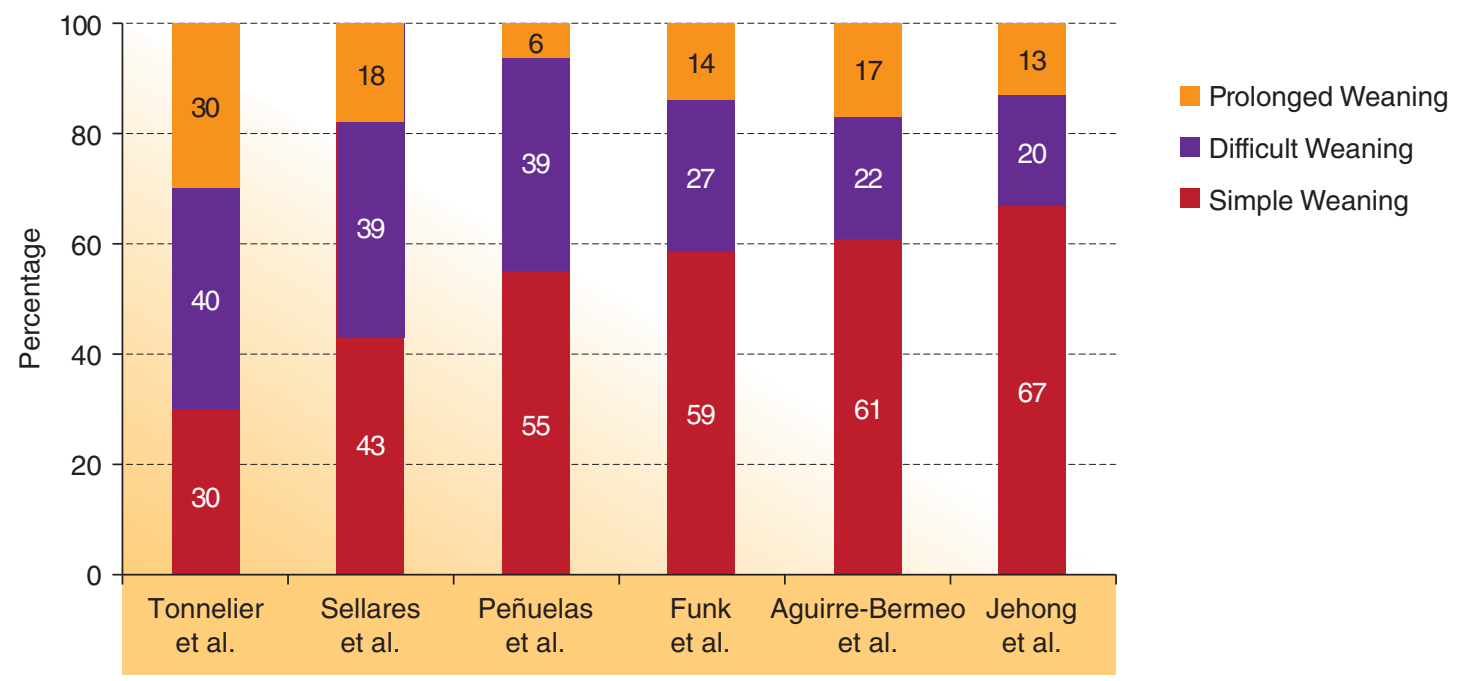

Figure 2. Weaning groups incidence in all studies.

\section{PROLONGED MECHANICAL VENTILATION}

Classically, prolonged MV is defined as the necessity of MV of six or more hours per day for at least 21 consecutive days ${ }^{63}$. Current data show that the duration of MV in the prolonged weaning group (as classified by the consensus conference criteria) is around 15-20 days. Possibly, a relevant percentage of patients in the prolonged weaning group belong also to the prolonged MV group.

\section{Mechanisms Related to Prolonged Mechanical Ventilation}

There are modifiable and non-modifiable factors that can cause a prolonged dependence on the ventilator (Table 3$)^{64}$. The non-modifiable factors include chronic diseases such as COPD, chronic congestive heart failure, and neuromuscular disorders. In these scenarios, physicians have to optimize the treatment according to each condition in order to diminish the impact of the basal disease on the duration of ventilation. For example, the use of NIMV immediately after extubation in COPD patients, or the use of diuretics and vasodilators during MV and after extubation in chronic heart failure.

The most important factors that could improve the outcomes in prolonged MV patients are modifiable and are described below.

\section{ASSESSMENT OF THE CAPACITY to BREathe Spontaneously}

A delay in identifying the ability to breathe spontaneously could be a cause of prolonged MV. A daily evaluation of the capacity to breathe spontaneously has to be made. Jubran et al. ${ }^{65}$ 
TABle 2. Outcomes of the different studies according to the consensus conference

\begin{tabular}{|c|c|c|c|c|}
\hline Variable & Study & Simple weaning & Difficult weaning & Prolonged weaning \\
\hline \multirow[t]{6}{*}{ Re-intubation } & Funk et al. ${ }^{57}$ & $13 \%$ & $7 \%$ & $5 \%$ \\
\hline & Sellares et al. ${ }^{47}$ & $15 \%$ & $19 \%$ & $33 \%$ \\
\hline & Peñuelas et al. ${ }^{59}$ & $10 \%$ & $10 \%$ & $16 \%$ \\
\hline & Tonnelier et al. ${ }^{60}$ & $0 \%$ & $6 \%$ & $15 \%$ \\
\hline & Aguirre-Bermeo et al. ${ }^{61}$ & $7 \%$ & $19 \%$ & $73 \%$ \\
\hline & Jeong et al. ${ }^{62}$ & $0 \%$ & $21 \%$ & $32 \%$ \\
\hline \multirow[t]{5}{*}{ Tracheostomy } & Funk et al. ${ }^{57}$ & $7 \%$ & $15 \%$ & $68 \%$ \\
\hline & Sellares et al. ${ }^{47}$ & $8 \%$ & $9 \%$ & $39 \%$ \\
\hline & Peñuelas et al. ${ }^{59}$ & $6 \%$ & $6 \%$ & $10 \%$ \\
\hline & Aguirre-Bermeo et al. ${ }^{61}$ & $3 \%$ & $10 \%$ & $50 \%$ \\
\hline & Jeong et al. ${ }^{62}$ & $7 \%$ & $24 \%$ & $64 \%$ \\
\hline \multirow[t]{6}{*}{ ICU stay (days)* } & Funk et al. ${ }^{57}$ & $4(1-9)$ & $11(7-20)$ & $27(18-37)$ \\
\hline & Sellares et al. ${ }^{47}$ & $11 \pm 12$ & $12 \pm 8$ & $21 \pm 13$ \\
\hline & Peñuelas et al. ${ }^{59}$ & $6(3-10)$ & $9(6-15)$ & $18(14-25)$ \\
\hline & Tonnelier et al. ${ }^{60}$ & $10 \pm 9$ & $16 \pm 15$ & $30 \pm 25$ \\
\hline & Aguirre-Bermeo et al. ${ }^{61}$ & $10 \pm 7$ & $17 \pm 13$ & $24 \pm 15$ \\
\hline & Jeong et al. ${ }^{62}$ & $5(3-9)$ & $10(6-14)$ & $21(15-32)$ \\
\hline \multirow[t]{6}{*}{ ICU mortality } & Funk et al. ${ }^{57}$ & $3 \%$ & $1 \%$ & $22 \%$ \\
\hline & Sellares et al. ${ }^{47}$ & $13 \%$ & $11 \%$ & $42 \%$ \\
\hline & Peñuelas et al. ${ }^{59}$ & $7 \%$ & $7 \%$ & $13 \%$ \\
\hline & Tonnelier et al. ${ }^{60}$ & $0 \%$ & $2 \%$ & $18 \%$ \\
\hline & Aguirre-Bermeo et al. ${ }^{61}$ & $3 \%$ & $5 \%$ & $38 \%$ \\
\hline & Jeong et al. ${ }^{62}$ & $5 \%$ & $7 \%$ & $37 \%$ \\
\hline
\end{tabular}

* Data are presented median (IR) or means \pm SD.

ICU: intensive care unit.

performed a randomized study to compare weaning duration with pressure support versus unassisted breathing through a tracheostomy collar in patients transferred to a long-term acute care hospital for weaning from prolonged MV. A total of 500 patients were enrolled. In this study, 160 patients (32\%) who were enrolled were disconnected from the ventilator at the first attempt (screening procedure). A total of 316 patients were finally randomized.
The authors found that unassisted breathing through a tracheostomy, compared with pressure support, resulted in a shorter median weaning time (19 versus 15 days; $\mathrm{p}=0.004$ ).

\section{NUTRITION}

Nutritional problems can predispose to prolong MV or can worsen the clinical situation 
TABLE 3. Different scenarios that the physicians need to consider when addressing prolonged mechanical ventilation patients

\begin{tabular}{|c|c|}
\hline Scenarios & Possible solutions \\
\hline COPD & $\begin{array}{l}\text { Avoid ventilator over-assistance, bronchodilators, } \\
\text { early use of NIMV. }\end{array}$ \\
\hline Heart failure & Diuretics, vasodilators, control of heart rate. \\
\hline Weakness & $\begin{array}{l}\text { Early physiotherapy, active mobilization, } \\
\text { appropriate nutrition. }\end{array}$ \\
\hline Delirium & $\begin{array}{l}\text { Withdraw sedatives and opiates as soon as } \\
\text { possible; consider specific drugs (i.e. quetiapine, } \\
\text { dexmedetomidine, etc.) and non-pharmacological } \\
\text { interventions (cognitive and sensorial } \\
\text { stimulation). }\end{array}$ \\
\hline All scenarios & $\begin{array}{l}\text { Daily evaluation of the capacity to breathe } \\
\text { spontaneously. } \\
\text { Glycemic control, treatment of infections, minimize } \\
\text { sleep disturbances, management of electrolytic } \\
\text { disorders, adequate haemoglobin levels. }\end{array}$ \\
\hline
\end{tabular}

in patients with prolonged MV. The effects of malnutrition on respiratory function include reduction of respiratory muscle mass, leading to reductions in respiratory muscle strength and endurance ${ }^{66}$. Therefore, patients with prolonged MV must have an integral and individualized nutritional management.

\section{WEAKNESS}

Weakness of ICU patients is a factor related to prolonged weaning, extubation failure, and prolonged MV. The main factors that can develop or worsen muscle weakness are multiorgan failure, sepsis, severity of illness, duration of ICU stay, vasopressor support, female gender, renal failure, renal replacement therapy, parenteral nutrition, and hyperglycaemia $^{67}$. One effective procedure to decrease the severity of muscle weakness is the application of early physiotherapy ${ }^{68}$.

\section{DELIRIUM}

As much as $40 \%$ of patients under MV may suffer delirium ${ }^{69}$. These patients are at high risk of prolonged duration of $\mathrm{MV}$, length of stay, tracheostomy, and mortality ${ }^{70,71}$. The use of specific drugs (risperidone, dexmedetomidine, quetiapine) and non-pharmacological interventions (patient daily orientation, early mobilization, improvement of sleep quality) could control and decrease the incidence of delirium $^{72,73}$.

\section{SEDATION}

Early deep sedation has been associated with a delay of extubation and higher mortality ${ }^{74}$. Schweickert et al. ${ }^{72}$ performed a randomized study comparing early exercise and mobilization during periods of daily interruption of sedation (intervention group) with daily interruption of sedation with therapy as ordered by the primary care team (control group). They found a significant decrease in duration of delirium ( 2 versus 4 days; $\mathrm{p}=0.03$ ) and in the duration of MV (3 versus 6 days; $p=0.02$ ) in the intervention group compared to the control group.

\section{CONCLUSIONS}

In the majority of patients, weaning is a simple process and has favourable outcomes. The patients of prolonged weaning groups have worst outcomes and must be identified early. Additional therapies such as non-invasive mechanical ventilation and closed-loop modalities could be used during weaning in a specific group of patients. Finally, patients with 


\section{prolonged mechanical ventilation require par- ticular management and surveillance, includ- ing a global approach that takes into account physical, nutritional, and individualized clin- ical measures.}

\section{REFERENCES}

1. Esteban A, Ferguson ND, Meade MO, et al. Evolution of mechanical ventilation in response to clinical research. Am J Respir Crit Care Med. 2008; 177:170-7.

2. Cabello B, Mancebo J. Work of breathing. Intensive Care Med. 2006;32:1311-4.

3. Esteban A, Alia I, Ibanez J, Benito S, Tobin MJ. Modes of mechanical ventilation and weaning. A national survey of Spanish hospitals. The Spanish Lung Failure Collaborative Group. Chest. 1994;106:1188-93.

4. Esteban A, Anzueto A, Alia I, et al. How is mechanical ventilation employed in the intensive care unit? An international utilization review. Am J Respir Crit Care Med. 2000;161:1450-8

5. Esteban A, Anzueto A, Frutos F, et al. Characteristics and outcomes in adult patients receiving mechanical ventilation: a 28-day international study. JAMA. 2002;287:345-55.

6. Sassoon CS, Mahutte CK. Airway occlusion pressure and breathing pattern as predictors of weaning outcome. Am Rev Respir Dis. 1993;148:860-6.

7. Epstein SK. Etiology of extubation failure and the predictive value of the rapid shallow breathing index. Am J Respir Crit Care Med. 1995;152:545-9.

8. Tobin M, Jubran A. Weaning from mechanical ventilation. In: Principles and Practice of Mechanical Ventilation. Tobin M (Ed.). New York, NY: McGrawHill; 2012:1307-51.

9. Esteban A, Frutos F, Tobin MJ, et al. A comparison of four methods of weaning patients from mechanical ventilation. Spanish Lung Failure Collaborative Group. N Engl J Med. 1995;332:345-50.

10. Mancebo J. Weaning from artificial ventilation. Monaldi Arch Chest Dis. 1998;53:350-4

11. Esteban A, Frutos-Vivar F, Muriel A, et al. Evolution of mortality over time in patients receiving mechanical ventilation. Am J Respir Crit Care Med. 2013;188:220-30.

12. Brochard L, Rauss A, Benito S, et al. Comparison of three methods of gradual withdrawal from ventilatory support during weaning from mechanical ventilation. Am J Respir Crit Care Med. 1994;150:896-903.

13. Yang KL, Tobin MJ. A prospective study of indexes predicting the outcome of trials of weaning from mechanical ventilation. N Engl J Med. 1991;324: 1445-50.

14. Shah C, Kollef MH. Endotracheal tube intraluminal volume loss among mechanically ventilated patients. Crit Care Med. 2004;32:120-5.

15. Moran I, Cabello B, Manero E, Mancebo J. Comparison of the effects of two humidifier systems on endotracheal tube resistance. Intensive Care Med. 2011;37:1773-9

16. Esteban A, Alia I, Gordo F, et al. Extubation outcome after spontaneous breathing trials with T-tube or pressure support ventilation. Am J Respir Crit Care Med. 1997;156:459-65.

17. Cabello B, Thille AW, Roche-Campo F, et al. Physiological comparison of three spontaneous breathing trials in difficult-to-wean patients. Intensive Care Med. 2010;36:1171-9.

18. Marini JJ. Weaning from mechanical ventilation. N Engl J Med. 1991;324: 1496-8.

19. Mancebo J. Weaning from mechanical ventilation. Eur Respir J. 1996;9:1923-31.

20. Vassilakopoulos T, Roussos C, Zakynthinos S. Weaning from mechanical ventilation. J Crit Care. 1999;14:39-62.
21. McConville JF, Kress JP. Weaning patients from the ventilator. N Engl J Med. 2012;367:2233-9.

22. Jubran A, Tobin MJ. Pathophysiologic basis of acute respiratory distress in patients who fail a trial of weaning from mechanical ventilation. Am J Respir Crit Care Med. 1997;155:906-15.

23. Epstein SK, Ciubotaru RL. Influence of gender and endotracheal tube size on preextubation breathing pattern. Am J Respir Crit Care Med. 1996;154: $1647-52$.

24. Lemaire F, Teboul JL, Cinotti L, et al. Acute left ventricular dysfunction during unsuccessful weaning from mechanical ventilation. Anesthesiology 1988;69:171-9.

25. Gandhi SK, Powers JC, Nomeir AM, et al. The pathogenesis of acute pulmonary edema associated with hypertension. N Engl J Med. 2001;344:17-22.

26. Poppas A, Rounds S. Congestive heart failure. Am J Respir Crit Care Med. 2002;165:4-8

27. Mekontso-Dessap A, de Prost N, Girou E, et al. B-type natriuretic peptide and weaning from mechanical ventilation. Intensive Care Med. 2006;32:1529-36.

28. Mekontso Dessap A, Roche-Campo F, Kouatchet A, et al. Natriuretic peptide-driven fluid management during ventilator weaning: a randomized controlled trial. Am J Respir Crit Care Med. 2012;186:1256-63.

29. Kress JP, Hall JB. ICU-acquired weakness and recovery from critical illness N Engl J Med. 2014;370:1626-35.

30. Maher J, Rutledge F, Remtulla H, et al. Neuromuscular disorders associated with failure to wean from the ventilator. Intensive Care Med. 1995;21:737-43

31. Segredo V, Caldwell JE, Matthay MA, et al. Persistent paralysis in critically ill patients after long-term administration of vecuronium. $\mathrm{N}$ Engl J Med. 1992;327:524-8.

32. Decramer M, Lacquet LM, Fagard R, Rogiers P. Corticosteroids contribute to muscle weakness in chronic airflow obstruction. Am J Respir Crit Care Med. 1994;150:11-6.

33. Levine S, Nguyen T, Taylor N, et al. Rapid disuse atrophy of diaphragm fibers in mechanically ventilated humans. N Engl J Med. 2008;358:1327-35

34. Grosu HB, Lee YI, Lee J, et al. Diaphragm muscle thinning in patients who are mechanically ventilated. Chest. 2012;142:1455-60.

35. Demoule A, Jung B, Prodanovic H, et al. Diaphragm dysfunction on admission to the intensive care unit. Prevalence, risk factors, and prognostic impact-a prospective study. Am J Respir Crit Care Med. 2013;188:213-9.

36. Hooijman PE, Beishuizen A, Witt CC, et al. Diaphragm muscle fiber weakness and ubiquitin-proteasome activation in critically ill patients. Am Respir Crit Care Med. 2015;191:1126-38.

37. Bouadma L, Lellouche F, Cabello B, et al. Computer-driven management of prolonged mechanical ventilation and weaning: a pilot study. Intensive Care Med. 2005;31:1446-50.

38. Lellouche F, Mancebo J, Jolliet P, et al. A multicenter randomized trial of computer-driven protocolized weaning from mechanical ventilation. Am J Respir Crit Care Med. 2006;174:894-900.

39. Rose L, Presneill JJ, Johnston L, Cade JF. A randomised, controlled trial of conventional versus automated weaning from mechanical ventilation using SmartCare/PS. Intensive Care Med. 2008;34:1788-95.

40. Schadler D, Engel C, Elke G, et al. Automatic control of pressure support for ventilator weaning in surgical intensive care patients. Am J Respir Crit Care Med. 2012;185:637-44.

41. Burns KE, Meade MO, Lessard MR, et al. Wean earlier and automatically with new technology (the WEAN study). A multicenter, pilot randomized controlled trial. Am J Respir Crit Care Med. 2013;187:1203-11.

42. Arnal JM, Wysocki M, Novotni D, et al. Safety and efficacy of a fully closedloop control ventilation (IntelliVent-ASV(R)) in sedated ICU patients with acute respiratory failure: a prospective randomized crossover study. Intensive Care Med. 2012;38:781-7.

43. Lellouche F, Bouchard PA, Simard S, L'Her E, Wysocki M. Evaluation of fully automated ventilation: a randomized controlled study in post-cardiac surgery patients. Intensive Care Med. 2013;39:463-71.

44. Nava S, Ambrosino N, Clini E, et al. Noninvasive mechanical ventilation in the weaning of patients with respiratory failure due to chronic obstruc- 
tive pulmonary disease. A randomized, controlled trial. Ann Intern Med. 1998;128:721-8.

45. Girault C, Bubenheim M, Abroug F, et al. Noninvasive ventilation and weaning in patients with chronic hypercapnic respiratory failure: a randomized multicenter trial. Am J Respir Crit Care Med. 2011;184:672-9.

46. Nava S, Gregoretti C, Fanfulla F, et al. Noninvasive ventilation to prevent respiratory failure after extubation in high-risk patients. Crit Care Med. 2005;33:2465-70.

47. Ferrer M, Sellares J, Valencia M, et al. Non-invasive ventilation after extubation in hypercapnic patients with chronic respiratory disorders: randomised controlled trial. Lancet. 2009;374:1082-8.

48. Esteban A, Frutos-Vivar F, Ferguson ND, et al. Noninvasive positive-pressure ventilation for respiratory failure after extubation. N Engl J Med. 2004; 350:2452-60.

49. Hilbert G, Gruson D, Portel L, Gbikpi-Benissan G, Cardinaud JP. Noninvasive pressure support ventilation in COPD patients with postextubation hypercapnic respiratory insufficiency. Eur Respir J. 1998;11:1349-53.

50. Auriant I, Jallot A, Herve P, et al. Noninvasive ventilation reduces mortality in acute respiratory failure following lung resection. Am J Respir Crit Care Med. 2001;164:1231-5.

51. Squadrone V, Coha M, Cerutti E, et al. Continuous positive airway pressure for treatment of postoperative hypoxemia: a randomized controlled trial. JAMA. 2005;293:589-95.

52. Chanques G, Riboulet F, Molinari N, et al. Comparison of three high flow oxygen therapy delivery devices: a clinical physiological cross-over study. Minerva Anestesiol. 2013;79:1344-55.

53. Maggiore SM, Idone FA, Vaschetto R, et al. Nasal high-flow versus Venturi mask oxygen therapy after extubation. Effects on oxygenation, comfort, and clinical outcome. Am J Respir Crit Care Med. 2014;190:282-8.

54. Stephan F, Barrucand B, Petit P, et al. High-flow nasal oxygen vs noninvasive positive airway pressure in hypoxemic patients after cardiothoracic surgery: A randomized clinical trial. JAMA. 2015;313:2331-9.

55. Hernandez G, Vaquero C, Gonzalez P, et al. Effect of postextubation highflow nasal cannula vs conventional oxygen therapy on reintubation in low-risk patients: A randomized clinical trial. JAMA. 2016;315:1354-61.

56. Boles JM, Bion J, Connors A, et al. Weaning from mechanical ventilation. Eur Respir J. 2007;29:1033-56.

57. Funk GC, Anders S, Breyer MK, et al. Incidence and outcome of weaning from mechanical ventilation according to new categories. Eur Respir J. 2010; 35:88-94.

58. Sellares J, Ferrer M, Cano E, et al. Predictors of prolonged weaning and survival during ventilator weaning in a respiratory ICU. Intensive Care Med. 2011;37:775-84.
59. Penuelas O, Frutos-Vivar F, Fernandez C, et al. Characteristics and outcomes of ventilated patients according to time to liberation from mechanical ventilation. Am J Respir Crit Care Med. 2011;184:430-7.

60. Tonnelier A, Tonnelier JM, Nowak E, et al. Clinical relevance of classification according to weaning difficulty. Respir Care. 2011;56:583-90.

61. Aguirre-Bermeo H, Bottiroli M, Cuartero M, et al. Outcomes of weaning from mechanical ventilation. Intensive Care Med. 2011;37:S189.

62. Jeong BH, Ko MG, Nam J, et al. Differences in clinical outcomes according to weaning classifications in medical intensive care units. PLoS One. 2015; 10:e0122810.

63. White AC. Long-term mechanical ventilation: management strategies. Respir Care. 2012;57:889-97; discussion 98-9.

64. MacIntyre NR, Epstein SK, Carson S, et al. Management of patients requiring prolonged mechanical ventilation: report of a NAMDRC consensus conference. Chest. 2005;128:3937-54.

65. Jubran A, Grant BJ, Duffner LA, et al. Effect of pressure support vs unassisted breathing through a tracheostomy collar on weaning duration in patients requiring prolonged mechanical ventilation: a randomized trial JAMA. 2013;309:671-7.

66. Ambrosino N, Clini E. Long-term mechanical ventilation and nutrition. Respir Med. 2004;98:413-20.

67. Doherty N, Steen CD. Critical illness polyneuromyopathy (CIPNM); rehabilitation during critical illness. Therapeutic options in nursing to promote recovery: a review of the literature. Intensive Crit Care Nurs. 2010 26:353-62.

68. Hodgson CL, Berney S, Harrold M, Saxena M, Bellomo R. Clinical review early patient mobilization in the ICU. Crit Care. 2013;17:207.

69. Ely EW, Inouye SK, Bernard GR, et al. Delirium in mechanically ventilated patients: validity and reliability of the confusion assessment method for the intensive care unit (CAM-ICU). JAMA. 2001;286:2703-10.

70. Ely EW, Shintani A, Truman B, et al. Delirium as a predictor of mortality in mechanically ventilated patients in the intensive care unit. JAMA. 2004; 291:1753-62.

71. Mehta S, Cook D, Devlin JW, et al. Prevalence, risk factors, and outcomes of delirium in mechanically ventilated adults. Crit Care Med. 2015;43:557-66

72. Schweickert WD, Pohlman MC, Pohlman AS, et al. Early physical and occupational therapy in mechanically ventilated, critically ill patients: a randomised controlled trial. Lancet. 2009;373:1874-82.

73. Schweickert WD, Kress JP. Implementing early mobilization interventions in mechanically ventilated patients in the ICU. Chest. 2011;140:1612-7.

74. Shehabi Y, Chan L, Kadiman S, et al. Sedation depth and long-term mortality in mechanically ventilated critically ill adults: a prospective longitudinal multicentre cohort study. Intensive Care Med. 2013;39:910-8. 